\title{
Efficiency Evaluation on Construction Industrial Circular Economy based on Improved DEA Model
}

\author{
Liu Shengguo Song Xiaodong \\ School of Economics and Management, Beihang University, Beijing, China
}

\begin{abstract}
Based on the characteristics of circular economy, the improved data envelopment analysis model is proposed with nonexpected inputs (waste utilization) and non-expected outputs (waste emissions). Then, the circular economic efficiency of China's construction industry from 2006 to 2010 is analyzed. The results show that the overall circular economic efficiency of China's construction industry is on the rise, and scale efficiency is slowly to achieve optimal, but the apparent inadequacy of pure technical efficiency affect the development of China's circular economic in construction industry.
\end{abstract}

Keywords: data envelopment analysis; construction industry; efficiency of circular economy; non-expected input; nonexpected output

\section{INTRODUCTION}

Under the big background of economic rapid growth, and the speeding up of industrialization and urbanization in China, construction industry has also been in a period of rapid development since the end of 20th century. But it has encountered the bottleneck of resources lacks and environmental protection. Therefore, construction industry needs to develop circular economy vigorously. In fact, the circular economy in Chinese construction industry has been developed from the ear- liest comprehensive resources utilization and terminal pollution control to clean production, green manufacturing and green reengineering of business process, during which circular economy in construction industry has been developed into practical application from the conception interpretation and great achievements in new technologies for recycling, new equipments and techniques have been obtained. Therefore, to analyze and evaluate the efficiency of construction industrial circular economy will provide important information for the management and planning of construction industry.

\section{LITERATURE REVIEW}

As for efficiency evaluation, there are many traditional methods using single indicator or complex and multiple indicators of production or finance. But it's rare of static or dynamic quantitative studies on a certain industry from the view of ecological economics. Circular economy, as a kind of ecological economy, is both a model of economic development and a technological paradigm. So there are circular economy operation efficiency, resources allocation efficiency and technical efficiency (TE).

Most foreign researches on circular economy operation efficiency focused on ecoefficiency. The World Business Council for Sustainable Development (WBCSD), for example, promoted eco-efficiency as a "combination of business and sustaina- 
ble development" [1-2]. To companies, eco-efficiency means "conservation of resources and increase of competitiveness" [3]. In 1998, Organization for Economic Co-operation and Development (OECD) defined eco-efficiency as the efficiency that natural resources meet human needs from broad aspect combining welfare, competitiveness, impact on ecology of products throughout the life cycle, utilization of natural resources and environmental carrying capacity [4]. In the industry level, foreign researches also made a lot of achievements on ecological efficiency of circular economy. J. Korhonen et al. (2004) used DEA model to analyze the ecological efficiency of 24 power plants in one European country through two kinds of methods [5]. From the perspective of ecological economics and industry ecology, Kuosmanen et al. (2005) replaced the discharge pollutants index with environmental pressure index, and used DEA model to calculate and compare the relative ecological efficiency of three town highway transportation industry in Finland [6].

The research on circular economy efficiency in China is not enough, let alone of a certain industry. Inspired by overseas researches, Tian (2003), Chu et al.(2006) believed that "the nature of circular economy is to improve eco-efficiency, and eco-efficiency is an appropriate measure of circular economy"[7-8]; Zhou(2003) introduced the eco-efficiency conception applied widely in OECD countries, and conducted pilot study and design on the indicator system of circular economy evaluation using that of the eco-efficiency as a reference [9]. All of the above studies provided theoretical basis and method attempt for the research on operation efficiency of circular economy, but all are qualitative research, ignore TE of circular economy and that the circular economy is a new technology model.
Circular economy system is a complex system with multi-input and multi-output, so a quantitative and dynamic evaluation on efficiency of circular economy in Chinese construction industry is studied from the ecological and economic view using the data envelopment analysis (DEA) model based on the former studies in this paper.

\section{EVALUATION METHOD BASED ON DEA}

Charnes, Cooper and Rhodes (1978) firstly invented a method using DEA model(C2R) to measure the efficiency of individual decision making units (DMUs) with multi-input and multi-output [10]. It is a linear programming method, a nonparametric statistics to evaluate whether the DMUs with multi-input and multioutput are technologically effective, based on the conception of relative efficiency. DEA method considers inputs and outputs separately, so it is strongly objective and practical due to its less calculation [11]. DEA method has been widely used in the fields of the advancement of technology and productivity, costs and benefits, resources allocation and technology innovation, etc., in recent years. A large number of theoretical literatures and actual data have shown that DEA method is one of the major comprehensive measurements of efficiency [12-14].

\subsection{The Basic DEA Model}

Suppose there are n DMUs, and each production activity of DMU has $m$ types of inputs, $\mathrm{X}_{\mathrm{i}}>0(\mathrm{i}=1,2, \ldots, \mathrm{m})$, and has $\mathrm{s}$ kinds of outputs, $Y_{r}>0(r=1,2, \ldots, s)$. Then any production activity can be expressed as vector pairs $\left(\mathrm{X}_{\mathrm{j}}, \mathrm{Y}_{\mathrm{j}}\right)$, where $\mathrm{X}_{\mathrm{j}}=$ $\left(x_{1 i}, x_{2 j}, \ldots, x_{m i}\right)^{T}, Y_{i}=\left(y_{1 i}, y_{2 i}, \ldots, y_{s j}\right)^{T}$. The $C^{2} R$ model for measuring efficiency based on inputs is as follows: 


$$
\begin{aligned}
& \max _{h_{j 0}}=\frac{\sum_{r=1}^{s} u_{r} y_{r j 0}}{\sum_{i=1}^{m} v_{i} x_{i j 0}} \\
& \text { s.t. } h_{j}=\frac{\sum_{r=1}^{s} u_{r} y_{r j}}{\sum_{i=1}^{m} v_{i} x_{i j}} \leq 1 \\
& u_{r} \geq 0, v_{i} \geq 0, j=1,2, \ldots, n
\end{aligned}
$$

Where $v_{i}$ and $u_{r}$ are the weights of inputs and outputs. Through CharnesCooper transformation and duality transformation, added slack variables $S^{+}$and remaining variables $S^{-}$, the equation(1) is changed into:

$\min \theta-\varepsilon E^{T}\left(s^{+}+s^{-}\right)$

$$
\begin{array}{ll}
\text { s.t } & \sum_{j=1}^{n} \lambda_{j} X_{j}+s^{-}=\theta X_{j 0} \\
& \sum_{j=1}^{n} \lambda_{j} Y_{j}-s^{+}=Y_{j 0} \\
& \lambda_{j} \geq 0, s^{-} \geq 0, s^{+} \geq 0, j=1,2, \ldots, n
\end{array}
$$

The $C^{2} R$ model can be used to evaluate whether the DMUs is of the optimal circular economy technology efficiency. However, the precondition is that each DMU is under the optimal scale returns, so the $\mathrm{C}^{2} \mathrm{R}$ model cannot be used to simply evaluate whether the TE of the DMUs re optimal. In fact, there is also the case to simply evaluate the technical efficiency under variable $\mathrm{SE}$ of DMUs, and then $\mathrm{BC}^{2}$ model should be used. $\mathrm{BC}^{2}$ model only adds a condition in equation(2):

$\sum_{i=1}^{n} \lambda_{j}=1$

The difference between the $\mathrm{C}^{2} \mathrm{R}$ and $\mathrm{BC}^{2}$ model lies in that efficiency in the $C^{2} R$ model is comprehensive efficiency of technical and scale efficiency, which can be called constant returns-to scale tech- nology efficiency (CRSTE), as for $\mathrm{BC}^{2}$ model, the efficiency is variable returns-to scale technology efficiency (VRSTE), which can be called pure technology efficiency.

\subsection{DEA Model for circular economy}

In general, the production process of an economic system DMU is to produce products with resources consumption. And the aim of evaluation on DMUs efficiency is to get more outputs with fewer inputs. The more outputs, the more efficient the DMUs are. During some processes of production, non-expected output besides products will be generated. For example, pollutants such as waste residue will be generated in construction industry. These two types of output objects should be treated differently minimize the nonexpected output while increasing the expected output and achieve a win-win in environmental protection and economic development, which is exactly the meaning of circular economy efficiency evaluation.

Support the inputs can be divided into expected input $(i=1,2, \ldots, l)$ and nonexpected input $(i=l+1, l+2, \ldots, m)$, and output also can be divided into expected output $(r=1,2, \ldots, k)$ and nonexpected output $(r=k+1, k+2, \ldots, s)$.then the efficiency evaluation indicator of $\mathrm{DMU}_{\mathrm{j}}$ was defined as:

$\max h_{j 0}=\frac{\sum_{r=1}^{k} u_{r} y_{r j 0}+\sum_{i=l+1}^{m} v_{i} x_{i j 0}}{\sum_{i=1}^{l} v_{i} x_{i j 0}+\sum_{r=k+1}^{s} u_{r} y_{r j 0}}$
st $h_{j}=\frac{\sum_{r=1}^{k} u_{r} y_{r j 0}+\sum_{i=l+1}^{m} v_{i} x_{i j 0}}{\sum_{i=1}^{l} v_{i} x_{i j 0}+\sum_{r=k+1}^{s} u_{r} y_{r j 0}} \leq 1$ 


$$
u_{r} \geq 0, v_{i} \geq 0, j=1,2, \ldots, n
$$

After transformation:

$\min \left[\theta-\varepsilon E^{T}\left(s^{d}+s^{u}+s^{g}+s^{b}\right)\right]$

st $\sum_{j=1}^{n} \lambda_{j} X_{j}+s^{d}=\theta x_{i 0}$

$\sum_{j=1}^{n} \lambda_{j} X_{j}-s^{u}=x_{i 0}$

$\sum_{j=1}^{n} \lambda_{j} Y_{j}^{g}-s^{g}=y_{j 0}^{g}$

$\sum_{j=1}^{n} \lambda_{j} Y_{j}^{b}+s^{b}=\theta y_{j 0}^{b}$

$\lambda, s^{b}, s^{g}, s^{d}, s^{u} \geq 0, \varepsilon>0, j=1,2$

\section{EFFICIENCY EVALUATION ON CHINESE CONSTRUCTION IN- DUSTRIAL CIRCULAR ECON- OMY}

\subsection{Evaluation indicators}

Efficiency of circular economy in construction industry means to obtain maximal products or profits and minimize pollution under the premise of vigorous development of circular economy. Evaluation indicators of circular economy efficiency in construction industry are indicators provided for managers to establish development target of circular economy and bring forward an improved plan, and for operator to refer.

According to the principle that the data have scientific properties, consistency and comparability, and also considering the data availability, our input and output indicators based on DEA model are listed in Table 1.
Tab. 1 Input and output indicators

\begin{tabular}{|c|c|}
\hline Item & Indicator \\
\hline expected input & $\begin{array}{l}\text { Number of enterprise } \\
\text { Number of employees } \\
\text { The total power of equip- } \\
\text { ment } \\
\text { Total capital }\end{array}$ \\
\hline $\begin{array}{l}\text { non-expected } \\
\text { input }\end{array}$ & Waste utilization \\
\hline expected output & $\begin{array}{l}\text { Industrial Added Value } \\
\text { Housing construction area } \\
\text { Total construction industry } \\
\text { contract } \\
\text { Total of profits and taxes }\end{array}$ \\
\hline $\begin{array}{l}\text { non-expected } \\
\text { output }\end{array}$ & $\begin{array}{l}\text { Waste residue emission } \\
\text { Wastewater emission } \\
\text { Waste-gas emission }\end{array}$ \\
\hline
\end{tabular}

In this paper, we select totally 31 provinces. To guarantee the reliability of the $\eta_{\text {ndex data, we extract the index data from }}$ China Construction Industry Statistics Yearbook.

\subsection{Circular economy efficiency anal- ysis on China's construction in- dustry}

The circular economy efficiency of Chinese construction industry, mainly including CRSTE, VRSTE and SE, are analyzed using the improved DEA model. The results are listed in Table 2.

Tab. 2 The circular economic efficiency of construction industry

\begin{tabular}{cccc}
\hline \multirow{2}{*}{ Year } & \multicolumn{3}{c}{ Annual Average value } \\
\cline { 2 - 4 } & CRSTE & VRSTE & SE \\
\hline 2006 & 0.835 & 0.897 & 0.931 \\
2007 & 0.828 & 0.881 & 0.940 \\
2008 & 0.873 & 0.919 & 0.950 \\
2009 & 0.889 & 0.925 & 0.961 \\
2010 & 0.913 & 0.929 & 0.983 \\
\hline Average & \multirow{2}{*}{0.078} & 0.032 & 0.052 \\
Increase & & & \\
\hline
\end{tabular}

The VRSTE in 2006 is 0.897 and 0.929 in 2010 , average increased by 0.032 , and for SE, it is 0.931 in 2006 and 0.983 in 2010 , average increased by 0.052 . It can be seen that the values of TE is larger than VRSSE form 2006 to 2010, and are increasing with low speed. It indicates that most growth of the circular economic 
inefficiency in Chinese construction industry lies in the SE.

It also can be seen that the scale benefit of Chinese construction industry is increasing but has not yet reached the optimal value, which indicates that the scale of construction enterprises in China need to be expanded. It is an indisputable fact that the concentration degree of Chinese construction industry is low.

\section{CONCLUSION}

Efficiency evaluation on industrial circular economy is one of the important parts of measuring the sustainable development of industry. Based on the existing ecoefficiency evaluation, the concept of efficiency evaluation on construction industrial circular economy is prompted. Pollutants emission is inducted into the DEA model as a non-expected input to analyze and evaluate the efficiency of construction industrial circular economy. The results show that the efficiency of construction industrial circular economy in China is not high as a whole, but is increasing. The main measure to improve the efficiency of construction industrial circular economy is to improve the pure technical efficiency.

\section{References}

[1] Lebn, M., State-of-Play Report, WBCSD Project on eco-efficiency metrics \& reporting, Geneva, World Business Council for Sustainable Development. 1998.

[2] WBCSD, Measuring Eco-Efficiency: A guide to reporting company performance, Geneva, World Business Council for Sustainable Development. 2000.

[3] Die Effizienz-Agentur NRW \& Wuppertal Institute, 4 Elements, 10 Factors, 1 Goal: Eco-efficiency, Duisburg, 2001.
[4] OECD, Eco-Efficiency, Paris, Organization for Economic Co-operation and Development. 1998.

[5] Pekka J Korhonen, Mikulas Luptacik. Eco-efficiency analysis of Power Plants: An extension of data envelopment analysis. European Journal of Operational Research, 2004, 154(2):437-446.

[6] Timo Kuosmanen, Mika Kortelainen. Measuring eco-efficiency of production with data envelopment analysis. Journal of industrial Ecology.2005, 9(4):59-72.

[7] C. X. Tian, L. P. Li, The nature of development of circular economy is to improve eco-efficiency [A] / / K. Zhang, Circular economy theory and practice $[\mathrm{M}]$. Beijing: China Environmental Science Press. 2003.

[8] D.J. Zhu, S.F. Qiu, Eco-efficiency is the appropriate measure of the economic cycle $[\mathrm{J}]$. China Population Resources and Environment, 2006, 16(5): 1-6.

[9] G.M. Zhou, H. Peng, F.Z. Cao, Circular economy and industrial ecoefficiency indicator system [J]. Urban Environment and Urban Ecology, 2003,16(6): 201-203.

[10] Charnes, Cooper, Rhodes, Measuring the efficiency of decision making units[J], European Journal of Operational Research, 1978, 2(6): 429-444.

[11] Y.H. Hu, S.H. He, Comprehensive evaluation method [M]. Beijing: Science Press, 2000.

[12] Y.H. Wu, DEA method and comparison of the production function method[J]. Systems Engineering, 1995, 13(3): 15-19.

[13] J.L. Yu, W.X. Han. DEA model in iron and steel enterprises in the application of economic evaluation [J]. Iron and steel, 1999, 34(2): 74-78. 
[14] Y.H. Wu, J. Xie, Business efficiency assessment study [J]. Productivity Research, 2006 (9): 236-238. 